\title{
Polymerization of Vinyl Ether by Use of Yttrium Silicate Gel as Solid Acid
}

\author{
Osamu MoriYa, ${ }^{1, \dagger}$ Toshio SugIZAKI, ${ }^{2}$ Atsuko KAMEJIMA, ${ }^{2}$ \\ Ken IwaKurA, ${ }^{3}$ Takeo KumOn, ${ }^{3}$ and Toshifumi KagEYAmA ${ }^{3}$ \\ ${ }^{1}$ Department of Applied Chemistry, National Defense Academy, Hashirimizu, Yokosuka 239-8686, Japan \\ ${ }^{2}$ Research Laboratory, Lintec Co., Nishiki-cho, Warabi 335-0005, Japan \\ ${ }^{3}$ Department of Industrial Chemistry, Kantogakuin University, Mutsuura, Kanazawa-ku, Yokohama 236-8501, Japan
}

(Received December 28, 2005; Accepted February 9, 2006; Published May 19, 2006)

\begin{abstract}
The gel of yttrium silicate was utilized as a solid catalyst for the polymerization of vinyl ethers. Several silicate gels showing the different element ratios of silicon and yttrium were prepared by the co-gelation of sodium metasilicate and yttrium(III) chloride from an acidic aqueous solution through neutralization by an aqueous ammonia. The polymerizations of ethyl vinyl ether and $n$-butyl vinyl ether proceeded readily in the presence of a catalytic amount of the silicate gel to give the corresponding polymers. When ethyl vinyl ether was used in benzene solution for the polymerization, the concentration of the monomer was not an essential factor which affected on the yield of the corresponding polymer. This demonstrated that the silicate gel provided an effective reaction environment for the polymerization with the catalytic sites. [doi:10.1295/polymj.PJ2005199]

KEY WORDS Yttrium Silicate / Rare Earth Metal / Vinyl Ether / Cationic Polymerization / Solid Acid /
\end{abstract}

Rare earth metal ion has been known and utilized as an effective Lewis acid in organic synthesis. ${ }^{1,2}$ Recently, the alkoxides and complexes of rare earth metals are applied to synthesis of polymeric compounds through ring opening polymerization. ${ }^{3-7}$ Furthermore, the solid silica derivatives containing the metals such as aluminum, chromium, zirconium, and vanadium have been employed for the well defined ring opening polymerization of 1,2-epoxide ${ }^{8}$ and lactones..$^{9-12}$ In these ring opening reactions, the silicate structure is recognized to provide an appropriate reaction environment with Brønsted and Lewis acidity. In addition, the solid catalyst, which can be removed readily from the reaction system by a simple filtration, should provide a convenient and practical procedure in polymer synthesis. ${ }^{13}$ These facts lead to the expectation that the silicate gel of rare earth metals, which shows Brønsted and/or Lewis acidity, can be a useful solid catalyst for the polymerization through a cationic specie. On the other hand, the silicate gels containing rare earth metals are known to show the specific physical and optical properties. ${ }^{14-18}$ Therefore, a large part of the investigations concerning the rare earth metal silicates has been developed from the interests in their physical properties. In other words, the utility of rare earth metal silicates as a solid catalyst in organic reactions has not been exploited so much.

By considering the information mentioned above, we have begun the investigations on the catalytic use of rare earth metal silicate in the field of polymer synthesis. As a first example, the ring-opening polymerization of oxetane by the catalytic uses of three kinds of the silicate gels such as yttrium (Y), neodymium, and samarium was studied. ${ }^{19}$ The obtained results indicated that yttrium silicate (1) was the most effective catalyst for the ring-opening polymerization among them. This seemed to reflect the reported Lewis acidities of the rare earth metals, in which $\mathrm{Y}$ shows a stronger acidity than neodymium and samarium. ${ }^{20}$ The observations also demonstrated that the solid silicate is enough effective for the polymerization progressed through a cationic specie. Such facts led us to another examination on the catalytic use of the silicate gel of $\mathrm{Y}$, which would provide an additional easy handling method for the cationic polymerization. As an appropriate example, our attention is directed to the polymerization of vinyl monomers. Since, the successful combination of vinyl monomers such as styrene and vinyl ethers with the resin containing sulfonic acid groups has been reported. ${ }^{21}$ In this report, to expand the usage of the silicate gel of $\mathrm{Y}$ in a cationic polymerization system, ethyl vinyl ether $(\mathbf{E V})$ and $n$ -

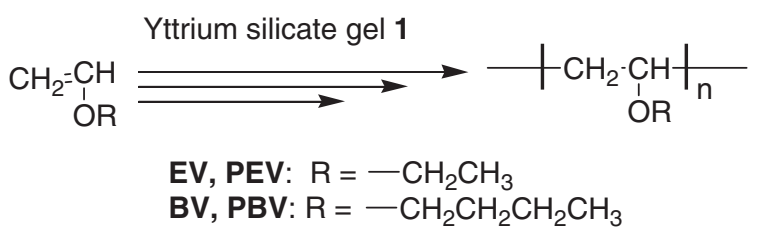

Scheme 1.

${ }^{\dagger}$ To whom correspondence should be addressed (Tel: +81-468-41-3810, Fax: +81-468-44-5901, E-mail: moriyaos@nda.ac.jp). 
butyl vinyl ether (BV) were chosen as the monomers and polymerized under various conditions.

\section{EXPERIMENTAL}

\section{General}

${ }^{1} \mathrm{H}$ NMR and ${ }^{13} \mathrm{C}$ NMR spectra were obtained on a JEOL FX-270 and JNM A-500 spectrometer in $\mathrm{CDCl}_{3}$. IR spectra were recorded on a JASCO FT/ IR 230. The specific surface areas were obtained by the Brunaur-Emmett-Teller (BET) method with a Collter Omnisorp 100CX using nitrogen as the absorbate. Gel permeation chromatographic (GPC) analysis was carried out on a TOSO HLC-8020 chromatograph equipped with a refractive index detector. TSK gel $\mathrm{G} 2500 \mathrm{H}, \mathrm{G} 2000 \mathrm{H}$, and $\mathrm{G} 1000 \mathrm{H}$, were connected in series and tetrahydrofuran (THF) was used as an eluent. Calibration for number-average molecular weight $\left(M_{\mathrm{n}}\right)$ and polydispersity $\left(M_{\mathrm{w}} / M_{\mathrm{n}}\right)$ was performed using standard polystyrenes. EV and BV were just distilled under argon atmosphere before use. Solvents employed for the reactions were distilled over an appropriate metal or a metal hydride before use. The alcohols were distilled over magnesium metal after the treatment with sodium metal. All other substrates including yttrium (III) chloride hexahydrate $\left(\mathrm{YCl}_{3}\right)$ were the best commercially available reagent grade and used as receipt.

\section{Preparation of Rare Earth Metal Silicate Gel}

The yttrium silicate gels 1 were prepared according to our reported procedure. ${ }^{19}$ To a solution of sodium metasilicate $\left(\mathrm{Na}_{2} \mathrm{SiO}_{3}\right)(28.4 \mathrm{~g}, 0.10 \mathrm{~mol})$ in water $(100 \mathrm{~mL}), \mathrm{pH}$ value of which was adjusted to be $c a$. 1 by using diluted hydrochloric acid (6 $[\mathrm{M}]), \mathrm{YCl}_{3}$ $(15.2 \mathrm{~g}, 0.05 \mathrm{~mol})$ in water $(100 \mathrm{~mL})$ was added. The aqueous solution was neutralized to $\mathrm{pH}=7$ by $10 \%$ of aqueous ammonia solution, which was added portion wise for over $3 \mathrm{~h}$ at room temperature. The solid precipitated from the solution was collected and washed several times with water and acetone. After drying at $700{ }^{\circ} \mathrm{C}$ for $3 \mathrm{~h}$ under air, the silicate gel $1 \mathrm{a}(11.1 \mathrm{~g}$, $61 \%$ based on $\mathrm{Si}, 58 \%$ based on yttrium, the element ratio of $\mathrm{Si} / \mathrm{Y}=2.1$ ) was obtained. The contents of silicon and yttrium in 1a were estimated by the results of gravimetric analysis and the specific surface area by BET method.

Analogously, the silicate gels containing the different ratios of silicon/yttrium such as $\mathrm{Si} / \mathrm{Y}=8.5$ (1b) and 19.0 (1c) were prepared by changing the feed ratios of the starting materials. The analytical data of $\mathbf{1}$ was shown in Table I.

\section{Polymerization of Vinyl Ether}

Typical procedure was as follows: The silicate gel 1a $(0.26 \mathrm{~g}, \mathrm{Y}=0.67 \mathrm{mmol}$ equiv., $10 \mathrm{~mol} \%)$ in a glass tube equipped with rubber septum was degassed and substituted with nitrogen at room temperature. Benzene $(4 \mathrm{~mL})$ and $\mathbf{E V}(0.49 \mathrm{~g}, 6.80 \mathrm{mmol})$ were injected by syringe and, then, the solution was stirred at $18{ }^{\circ} \mathrm{C}$ for $8 \mathrm{~h}$ After the reaction, 1a was filtered off and washed with methanol several times. The filtrate and washings were combined and evaporated under reduced pressure. The residual oil was dried under reduced pressure $(c a .15 \mathrm{mmHg})$ at room temperature to obtain the polymeric product of EV (PEV) ( $0.48 \mathrm{~g}$, 98\%) (Table II, Run 1); IR (neat) $2850\left(\mathrm{CH}_{2}\right.$, strong), $1480\left(\mathrm{CH}_{2}\right.$, medium $), 1360\left(\mathrm{CH}_{2}\right.$, medium $), 1120$ (C-O, strong) $\mathrm{cm}^{-1} ;{ }^{1} \mathrm{H}$ NMR $\left(\mathrm{CDCl}_{3}\right) \delta 0.95(\mathrm{~m}$, $3 \mathrm{H}, \mathrm{CH}_{3^{-}}$), 1.54-1.75 (br m, 2H, $-\mathrm{CH}_{2}-$ ); 3.30-3.65 (br m, 3H, -O-CH-, - $\mathrm{O}-\mathrm{CH}_{2-}$ ); ${ }^{13} \mathrm{C}$ NMR $\left(\mathrm{CDCl}_{3}\right) \delta$ $15.67\left(-\mathrm{CH}_{3}\right), 39.92\left(-\mathrm{CH}_{2}-\right), 64.24$ (-O-CH-), 73.61 $\left(-\mathrm{O}-\mathrm{CH}_{2}-\right) \cdot M_{\mathrm{n}}=8500, M_{\mathrm{w}} / M_{\mathrm{n}}=3.72$.

Analogously, the polymerizations of $\mathbf{B V}$ to give the corresponding polymeric product were carried out in the presence of a catalytic amount of the silicate gel 1, in which the polymers of $\mathbf{B V}$ (PBV) were isolated as an insoluble oil in methanol. The analytical data of PBV was as follows: IR (neat) 3450 (OH, weak), 2980 $\left(\mathrm{CH}_{2}\right.$, strong), $2850\left(\mathrm{CH}_{2}\right.$, strong), $1480\left(\mathrm{CH}_{2}\right.$, medium), $1360\left(\mathrm{CH}_{2}\right.$, medium), 1120 (C-O, strong) $\mathrm{cm}^{-1}$; ${ }^{1} \mathrm{H}$ NMR $\left(\mathrm{CDCl}_{3}\right) \delta 0.90\left(\mathrm{~m}, 3 \mathrm{H},-\mathrm{CH}_{3}\right), 1.54-1.84$ (br m, 6H, - $\mathrm{CH}_{2}-$ ), 3.30-3.65 (br m, 3H, -O-CH-, $\left.-\mathrm{O}-\mathrm{CH}_{2}-\right) ;{ }^{13} \mathrm{C}$ NMR $\left(\mathrm{CDCl}_{3}\right) \& 14.01\left(-\mathrm{CH}_{3}\right), 19.55$ $\left(-\mathrm{CH}_{2}-\right), 32.41\left(-\mathrm{CH}_{2}-\right), 40.52\left(-\underline{\mathrm{CH}}_{2}-\right), 68.88$ (-O$\underline{\mathrm{CH}}-), 73.69\left(-\mathrm{O}-\mathrm{CH}_{2}-\right)$.

The results and conditions were listed in Table II. The polymerizations conducted in other solvents were also carried out. The results were listed in Table III.

For the time-conversion and the conversion- $M_{\mathrm{n}}$ and $M_{\mathrm{w}} / M_{\mathrm{n}}$ curves shown in Figures 3, 4, and 5, the samples were taken by a syringe at the appropriate times during the polymerization which was carried out in $1.7 \mathrm{M}$ benzene solution of the monomer. The samples were employed for the measurements of ${ }^{1} \mathrm{H}$ NMR and GPC without removal of the solvent, respectively.

\section{Gravimetric Analysis}

The contents of Y and Si in the silicate gels $\mathbf{1}$ were determined by the same treatment for gravimetric analysis reported previously. ${ }^{19}$

Scanning Electron Microscopy with Energy Dispersive X-ray Microanalysis (SEM-EDXA)

The silicate gel 1a was measured with a SEM (HITACHI S-4700) equipped with an EDXA system (HITACHI E-1030). Micrograph of secondary electron images was taken at accelerating voltage of $5 \mathrm{keV}$, and EDXA was carried out at $20 \mathrm{keV}$ for spectrum analysis and element mapping ( 256 by 256 pixels). 
Polymerization of Vinyl Ether by Yttrium Silicate Gel

Table I. Preparation of the yttrium silicate gel $\mathbf{1}$

\begin{tabular}{|c|c|c|c|c|c|c|}
\hline $\begin{array}{l}\text { Silicate } \\
\text { gel }\end{array}$ & $\begin{array}{c}\text { Yield of } \\
\mathrm{Si} \\
\%\end{array}$ & $\begin{array}{c}\text { Yield of } \\
\text { yttrium } \\
\%\end{array}$ & $\begin{array}{c}\text { Content of } \\
\mathrm{Si} \\
\mathrm{mmol} / \mathrm{g}^{\mathrm{a}}\end{array}$ & $\begin{array}{c}\text { Content of } \\
\text { yttrium } \\
\mathrm{mmol} / \mathrm{g}^{\mathrm{a}}\end{array}$ & $\begin{array}{l}\text { Molar ratio } \\
\text { of } \\
\mathrm{Si} / \text { Yttrium }\end{array}$ & $\begin{array}{c}\text { Surface area } \\
\mathrm{m}^{2} / \mathrm{g}^{\mathrm{b}}\end{array}$ \\
\hline 1a & 61 & 58 & 5.49 & 2.59 & 2.1 & 150 \\
\hline $1 b$ & 68 & 71 & 8.59 & 1.01 & 8.5 & 195 \\
\hline $1 c$ & 65 & 68 & 14.89 & 0.78 & 19.0 & 195 \\
\hline
\end{tabular}

${ }^{a}$ Estimated by gravimetric analysis. ${ }^{b}$ Measured by BET method using nitrogen as the absorbate.

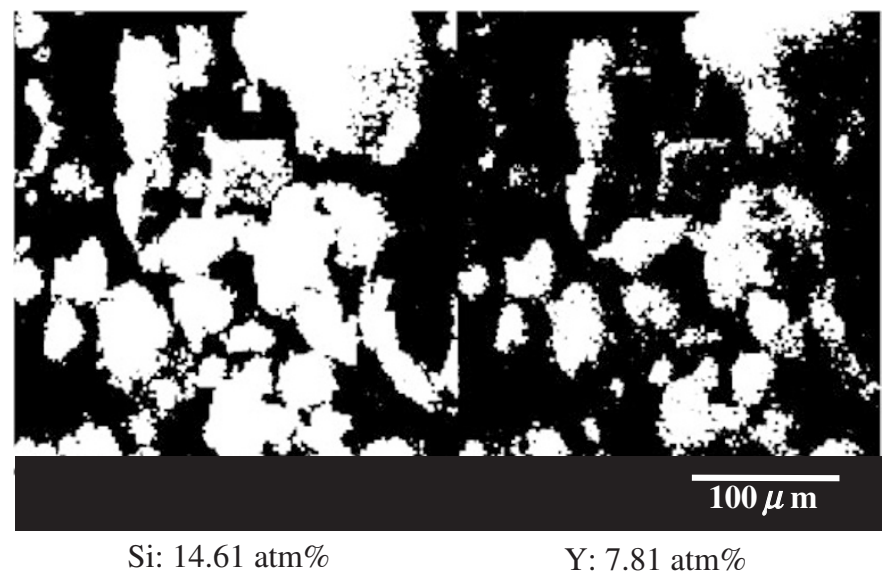

Figure 1. SEM-EDXA images of 1a.

The sample for SEM was fixed with photo-glue (vinyl acetate) on one end of copper tape adhered on a SEM stub and, then, adjusted the orientation by bending the copper tape. It was coated with Pt-Pd (80:20) in an ion-sputter coater (HITACHI OIE-6377) at $0.4 \mathrm{keV}$ with an electron current of $15 \mathrm{~mA}$ for $30 \mathrm{~s}$.

\section{RESULTS AND DISCUSSIONS}

\section{Preparation of Silicate Gel}

The silicate gels of yttrium 1 were prepared from $\mathrm{Na}_{2} \mathrm{SiO}_{3}$ and $\mathrm{YCl}_{3}$ by the same procedure reported before. ${ }^{19}$ The aqueous solution of $\mathrm{Na}_{2} \mathrm{SiO}_{3}$ and $\mathrm{YCl}_{3}$ was acidified by a diluted hydrochloric acid, where the $\mathrm{pH}$ value was adjusted to be $c a$. 2. Such acidic solution, in which polymeric or oligomeric silicic acid is reported to be hydrolyzed to monomeric one, was thought to be favorable for dispersing the rare earth metal species. ${ }^{22}$ The precipitation of the silicate gel was performed through neutralization of the acidic solution by using $10 \%$ aqueous ammonia solution. In this work, three kinds of the silicate gel 1a-c were prepared by changing the feed molar ratios of $\mathrm{Na}_{2} \mathrm{SiO}_{3}$ and $\mathrm{YCl}_{3}$. The results were shown in Table I. The contents of Si and Y in the gels, estimated by gravimetric analysis, were almost coincided with the feed molar ratios of $\mathrm{Na}_{2} \mathrm{SiO}_{3}$ and $\mathrm{YCl}_{3}$. The estimated ratios of $\mathrm{Si} / \mathrm{Y}$ were 2.1 for $\mathbf{1 a}, 6.5$ for $\mathbf{1 b}$, and $\mathbf{1 9 . 0}$ for $\mathbf{1 c}$, respectively. The surface areas of 1a-c measured by BET method were in the range from $150 \mathrm{~m}^{2} \mathrm{~g}^{-1}$ to $195 \mathrm{~m}^{2} \mathrm{~g}^{-1}$. These values may predict that the inner space of the gels is too narrow to progress the reaction in it and the reaction essentially proceeds on the surface. An additional evaluation of the silicate gel was made by SEM-EDXA analysis for the silicate gel 1a, containing a half element ratio of $\mathrm{Y}$ to Si. As shown in Figure 1, the map for Y overlapped almost completely with that for $\mathrm{Si}$ and the measured ratio of $\mathrm{Si} / \mathrm{Y}$ was $14.60 / 7.81$ on the surface of $1 \mathrm{a}$. The atomic ratio of $\mathrm{Y} / \mathrm{Si}$ on the surface showed good agreement with that estimated by gravimetric analysis of the gel 1a, which should be $\mathrm{Si} / \mathrm{Y}=2.1$. Such observations indicated that $\mathrm{Y}$ was dispersed well in polysiloxane network by forming Yttrium silicate structure.

\section{Polymerization of Vinyl Ether}

The polymerizations of $\mathbf{E V}$ and $\mathbf{B V}$ in the presence of a catalytic amount of the silicate gels $\mathbf{1}$ were conducted at $18{ }^{\circ} \mathrm{C}$ under a variety of conditions to elucidate the activities of the catalysts. The silicate gels $\mathbf{1}$ were calcined at $700^{\circ} \mathrm{C}$ for $1 \mathrm{~h}$ before use. The conversion of the monomer was calculated on the basis of ${ }^{1} \mathrm{H}$ NMR spectral data. As shown in Figure 2, the signals assigned to the protons of methylene and methine bonded to oxygen in PEV were appeared at $c a .3 .5 \mathrm{ppm}$. The signals due to other methylene and methyl protons were observed at $c a .1 .5$ and $0.95 \mathrm{ppm}$, respectively. The signals assigned to vinyl protons of the starting monomer $\mathbf{E V}$ were observed 


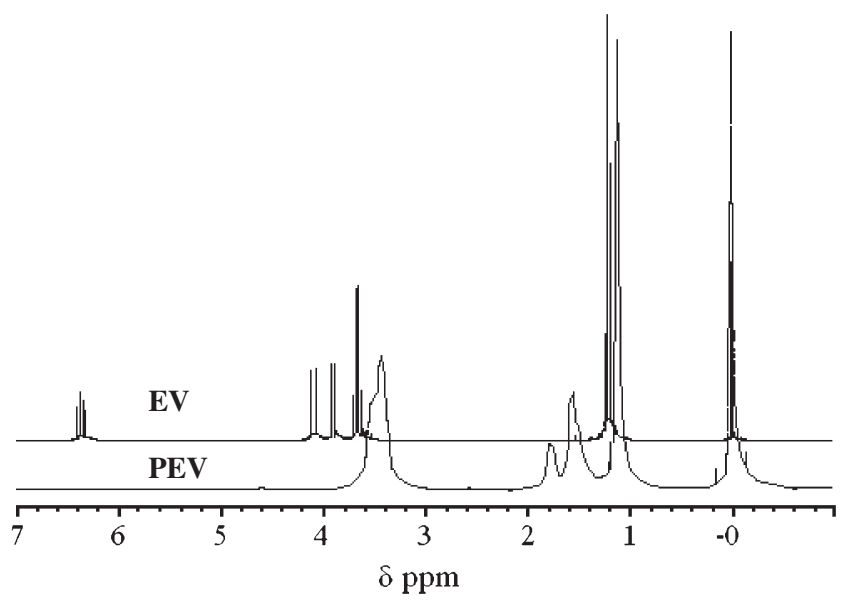

Figure 2. ${ }^{1} \mathrm{H} \mathrm{NMR}$ spectra $\left(\mathrm{CDCl}_{3}\right)$ of $\mathbf{E V}$ and PEV (Table II, Run 1).

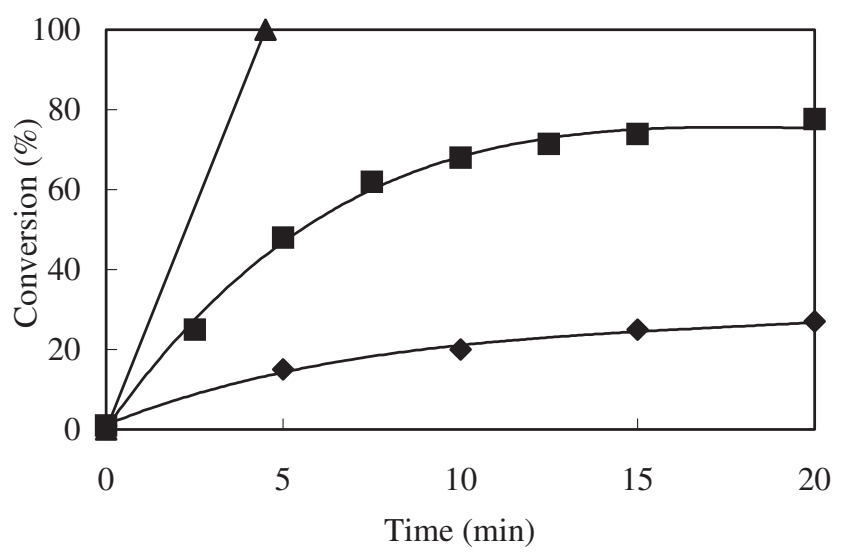

Figure 4. Relationships between time and conversion in the polymerization of $[1.7 \mathrm{M}]$ of $\mathbf{B V}$ in benzene with 1a: $(\bullet)$ $1 \mathrm{~mol} \%$; (অ): $5 \mathrm{~mol} \%$; (A) $10 \mathrm{~mol} \%$ of yttrium to $\mathbf{B V}$.

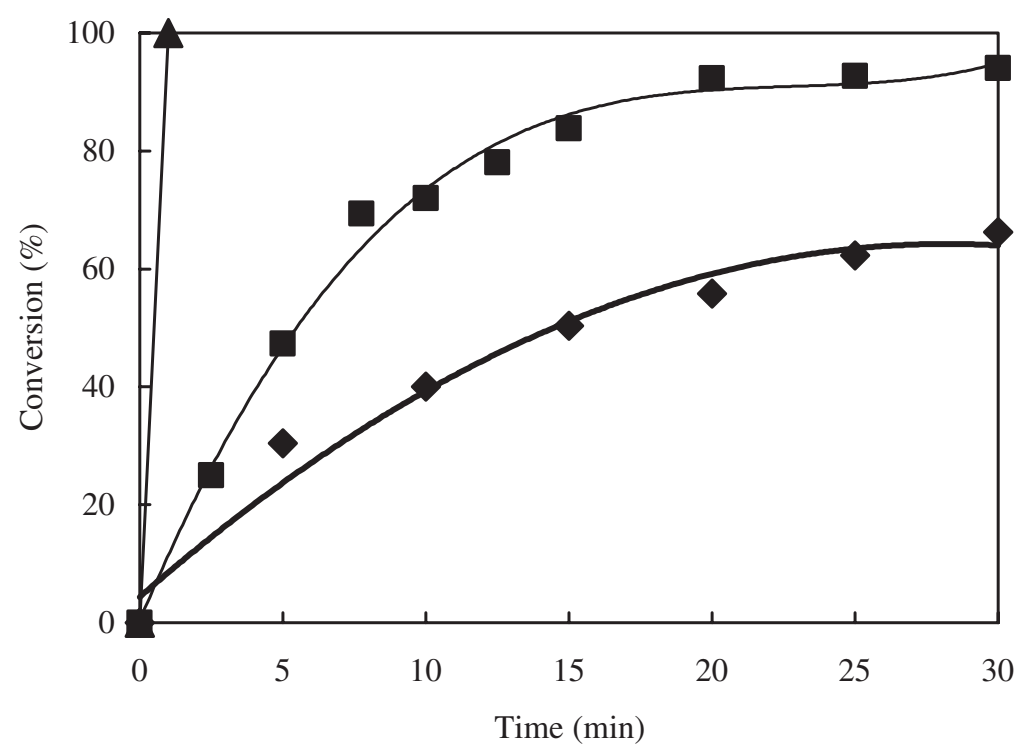

Figure 3. Relationships between time and conversion in the polymerization of $[1.7 \mathrm{M}]$ of $\mathbf{E V}$ in benzene with $1 \mathrm{a}$. $(\bullet): 1 \mathrm{~mol} \%$; $5 \mathrm{~mol} \%$; (А) $10 \mathrm{~mol} \%$ of yttrium to $\mathbf{E V}$.

at $3.91,4.10$, and $6.39 \mathrm{ppm}$. These were completely disappeared after the polymerization. In a similar manner, the corresponding signals due to methyl, methylene and methine protons of $\mathbf{B V}$ and PBV were observed in the ${ }^{1} \mathrm{H}$ NMR spectra with the additional signals for two methylene protons in the region from 1.36 to $1.82 \mathrm{ppm}$. These could be distinguished easily and were utilized for the calculations of conversion of the vinyl monomers in all the polymerizations mentioned here.

The relationships of time and conversion of the monomers were examined to obtain the information of the catalytic activity of $\mathbf{1}$. Figure 3 and 4 showed the time-conversion curves of $\mathbf{E V}$ and $\mathbf{B V}$, respectively, which were employed in $1.7 \mathrm{M}$ benzene solution at $18^{\circ} \mathrm{C}$. In these polymerizations, the silicate gel 1a was used as a representative catalyst and the contents of $\mathrm{Y}$ in the polymerization system were adjusted to be 1,5 , and $10 \mathrm{~mol} \%$ to the monomer by changing the amount of $\mathbf{1 a}$. The rate of consumption of the monomers reasonably increased according to the contents of $\mathrm{Y}$. When the polymerization was carried out with 1a containing $10 \mathrm{~mol} \%$ of $\mathrm{Y}$, the conversion of the monomer reached to $100 \%$ within $5 \mathrm{~min}$ in the both cases using $\mathbf{E V}$ and $\mathbf{B V}$. The results demonstrated that the solid acid 1a was enough effective for initiating the cationic polymerization of the monomers. However, the consumption of $\mathbf{B V}$ obviously became slow, when the content of $\mathrm{Y}$ decreased. In the uses of $\mathbf{1 a}$ containing 1 and $5 \mathrm{~mol} \%$ of $\mathrm{Y}$ to $\mathbf{B V}$, the conversions could not reach to $80 \%$ even after $8 \mathrm{~h}$ reaction. With the measurements of the rate of the polymerization, the relationships of conversion with $M_{\mathrm{n}}$ and $M_{\mathrm{w}} / M_{\mathrm{n}}$ in the above polymerization were also examined by 


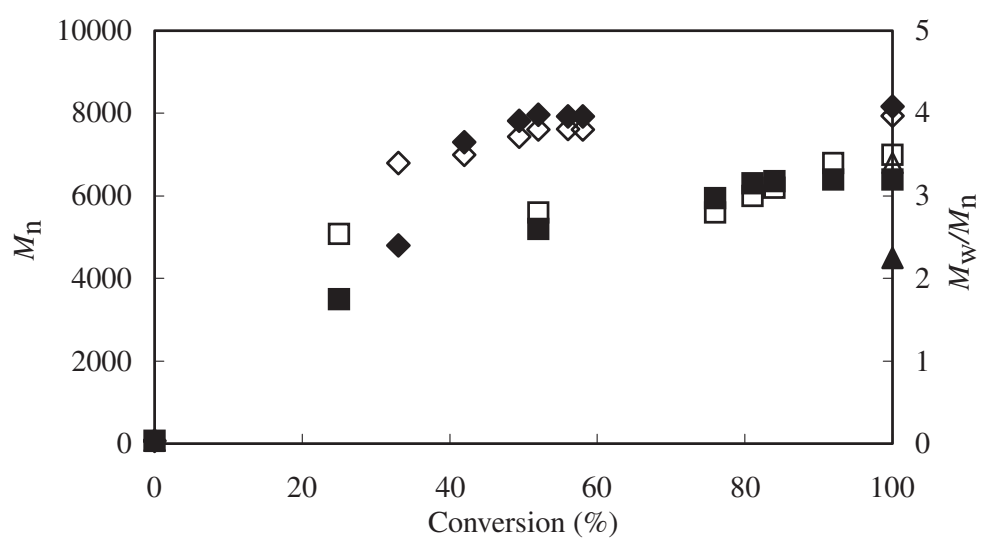

Figure 5. Relationships between conversion, $M_{\mathrm{n}}$, and $M_{\mathrm{w}} / M_{\mathrm{n}}$ in the polymerization of $[1.7 \mathrm{M}]$ of $\mathbf{E V}$ in benzene solution with 1 a. $(\diamond, \diamond): 1 \mathrm{~mol} \% ;(\mathbb{\square}, \square): 5 \mathrm{~mol} \% ;(\boldsymbol{\Delta}, \triangle): 10 \mathrm{~mol} \%$ of yttrium to $\mathbf{E V}$.

Table II. Polymerization of vinyl ether in the presence of silicate gel 1

\begin{tabular}{|c|c|c|c|c|c|c|c|}
\hline \multirow[b]{2}{*}{ Run } & \multicolumn{3}{|c|}{ Conditions $^{\mathrm{a}}$} & \multicolumn{4}{|c|}{ Poly(vinyl ether) ${ }^{\mathrm{a}}$} \\
\hline & $\begin{array}{c}\text { Silicate gel } \\
\text { (Molar ratio } \\
\text { of } \mathrm{Si} / \mathrm{Y} \text { ) }\end{array}$ & $\begin{array}{c}\text { Monomer } \\
\text { (Molar ratio of } \\
\text { Y/Monomer) }\end{array}$ & $\begin{array}{c}\text { Concentration of } \\
\text { monomer }[\mathrm{M}] \\
\text { (Solvent) }\end{array}$ & $\begin{array}{c}\text { Monomer } \\
\text { conversion }^{\mathrm{b}} \\
\%\end{array}$ & $\begin{array}{c}\text { Product } \\
\left(\text { Yield, } \%^{c} \text { ) }\right.\end{array}$ & $M_{\mathrm{n}}^{\mathrm{d}}$ & $M_{\mathrm{w}} / M_{\mathrm{n}}{ }^{\mathrm{d}}$ \\
\hline 1 & 1a $(2.1)$ & $\mathbf{E V}(0.01)$ & 13.6 (Benzene) & $>99$ & PEV (98) & 8500 & 3.72 \\
\hline 2 & $\mathbf{1 b}(8.5)$ & $\mathbf{E V}(0.01)$ & 13.6 (Benzene) & $>99$ & PEV (95) & 7800 & 2.66 \\
\hline 3 & $1 c(19.0)$ & $\mathbf{E V}(0.01)$ & 13.6 (Benzene) & $>99$ & PEV (>99) & 7000 & 3.25 \\
\hline 4 & 1a $(2.1)$ & BV $(0.01)$ & 13.6 (Benzene) & 92 & PBV (72) & 9500 & 1.85 \\
\hline 5 & $1 c(19.0)$ & $\mathbf{B V}(0.01)$ & 13.6 (Benzene) & 68 & PBV (46) & 8000 & 1.51 \\
\hline 6 & $\mathbf{1 a}(2.1)$ & $\mathbf{E V}(0.05)$ & 13.6 (Benzene) & $>99$ & PEV (>99) & 6800 & 3.72 \\
\hline 7 & 1a $(2.1)$ & $\mathbf{E V}(0.10)$ & 13.6 (Benzene) & $>99$ & PEV (>99) & 4600 & 3.86 \\
\hline 8 & 1a $(2.1)$ & $\mathbf{E V}(0.01)$ & - (None) & $>99$ & PEV (>99) & 6400 & 3.85 \\
\hline 9 & 1a $(2.1)$ & $\mathbf{E V}(0.01)$ & 6.8 (Benzene) & $>99$ & PEV (>99) & 8400 & 3.60 \\
\hline 10 & 1a $(2.1)$ & $\mathbf{E V}(0.01)$ & 3.4 (Benzene) & $>99$ & PEV (97) & 8200 & 3.62 \\
\hline 11 & $\mathbf{1 a}(2.1)$ & $\mathbf{E V}(0.01)$ & 0.9 (Benzene) & $>99$ & PEV (89) & 6200 & 3.20 \\
\hline 12 & 1a $(2.1)$ & $\mathbf{B V}(0.01)$ & - (None) & 87 & PBV (55) & 9200 & 1.71 \\
\hline 13 & 1a $(2.1)$ & BV $(0.01)$ & 3.4 (Benzene) & 72 & PBV (55) & 9400 & 1.83 \\
\hline 14 & 1a $(2.1)$ & BV $(0.01)$ & 0.9 (Benzene) & 43 & PBV (36) & 7800 & 1.85 \\
\hline $15^{\mathrm{e}}$ & 1a $(2.1)$ & $\mathbf{E V}(0.01)$ & 13.6 (Benzene) & $>99$ & PEV (97) & 8100 & 3.32 \\
\hline
\end{tabular}

${ }^{\mathrm{a}} 6.80 \mathrm{mmol}$ of vinyl ether was used for the polymerization carried out at $18{ }^{\circ} \mathrm{C}$ for $8 \mathrm{~h}$. ${ }^{\mathrm{b}}$ Estimated by ${ }^{1} \mathrm{H}$ NMR spectral data. ${ }^{\mathrm{c}}$ Isolated yield based on the weights of the materials. ${ }^{\mathrm{d}}$ Estimated by GPC (polystyrene standards). ${ }^{\mathrm{e}}$ Recycled 1a was employed after using two times for the polymerization.

GPC using polystyrene standards. In the relationships using BV as the monomer, the meaningful changes of molecular weights and the polydispersities of the products according to the content of $\mathrm{Y}$ were hardly obtained due to the decreased rates of the polymerization. Therefore, the results were shown only in the cases using $\mathbf{E V}$. Figure 5 showed that the $M_{\mathrm{n}} \mathrm{s}$ of PEV increased with the increases of conversion of $\mathbf{E V}$. When the conversion of $\mathbf{E V}$ was attained to $62 \%$ by the use of $1 \mathrm{~mol} \%$ of $\mathrm{Y}$, the $M_{\mathrm{n}}$ of PEV was $c a$. 8000. After complete consumption of $\mathbf{E V}$ in the polymerization containing $5 \mathrm{~mol} \%$ of Y, the $M_{\mathrm{n}}$ of PEV was 6200. The use of the larger amount of 1a such as $10 \mathrm{~mol} \%$ of Y content resulted in the formation of the lower $M_{\mathrm{n}}$ of PEV as estimated to be
4600. The variation of $M_{\mathrm{n}} \mathrm{s}$ according to the content of $\mathrm{Y}$ seemed to reflect the numbers of the active site on 1a for generating the cation species. On the basis of the information mentioned above, the following polymerizations with the isolation of the resulting PEV and PBV were carried out for $8 \mathrm{~h}$ under various conditions.

As shown in Table II, the isolated yields of PEV, obtained by simple distillation of the reaction mixture under reduce pressure, were almost in accord with the conversions of the starting $\mathbf{E V}$. This indicated that the reaction initiated by the silicate gel $\mathbf{1}$ proceeded primarily to form the corresponding polymeric product PEV. In the use of BV, the yields of PBV showed the smaller values compared to those of the conver- 
Table III. Polymerization of vinyl ether in various solvents

\begin{tabular}{|c|c|c|c|c|c|c|}
\hline \multirow[b]{2}{*}{ Run } & \multicolumn{2}{|c|}{ Conditions $^{\mathrm{a}}$} & \multicolumn{4}{|c|}{ Poly(vinyl ether) ${ }^{\mathrm{a}}$} \\
\hline & Monomer & $\begin{array}{c}\text { Concentration of } \\
\text { monomer }[\mathrm{M}] \\
(\text { Solvent })\end{array}$ & $\begin{array}{c}\text { Monomer } \\
\text { conversion }^{\mathrm{b}} \\
\% \\
\end{array}$ & $\begin{array}{c}\text { Product } \\
\left(\text { Yield, \% }{ }^{\mathrm{c}}\right)\end{array}$ & $M_{\mathrm{n}}^{\mathrm{d}}$ & $M_{\mathrm{w}} / M_{\mathrm{n}}^{\mathrm{d}}$ \\
\hline 1 & EV & 13.6 (Dichloromethane) & $>99$ & PEV (>99) & 8900 & 3.60 \\
\hline 2 & $\mathbf{E V}$ & 1.7 (Dichloromethane) & $>99$ & PEV (>99) & 8300 & 2.15 \\
\hline 3 & EV & 13.6 (Acetone) & $>99$ & PEV (>99) & 4900 & 2.34 \\
\hline 4 & $\mathbf{E V}$ & 1.7 (Acetone) & 62 & PEV (62) & 1800 & 1.60 \\
\hline 5 & EV & 13.7 (Acetonitrile) & $>99$ & PEV (95) & 2600 & 1.65 \\
\hline 6 & $\mathbf{E V}$ & 1.7 (Acetonitrile) & 0 & PEV (0) & - & - \\
\hline 7 & EV & 13.7 (Methanol) & $>99$ & Unknown & - & - \\
\hline 8 & EV & 13.7 (iso-Propylalcohol) & $>99$ & Unknown & - & - \\
\hline 9 & BV & 13.7 (Acetone) & 17 & PEV (17) & 7500 & 1.95 \\
\hline 10 & BV & 13.7 (Acetonitrile) & 8 & PEV (12) & - & - \\
\hline
\end{tabular}

${ }^{\mathrm{a}} 6.80 \mathrm{mmol}$ of vinyl ether was used for the polymerization carried out at $18{ }^{\circ} \mathrm{C}$ for $8 \mathrm{~h}$ with $1 \mathrm{a}$, the amount of which was adjusted to contain $1 \mathrm{~mol} \%$ of $\mathrm{Y}$ to the monomer. ${ }^{\mathrm{b}}$ Estimated by ${ }^{1} \mathrm{H}$ NMR spectral data. ${ }^{\mathrm{c}}$ Isolated yield based on the weights of the materials. ${ }^{\mathrm{d}}$ Estimated by GPC (polystyrene standards).

sions. The lower yields of PBV in comparison with the corresponding conversions were thought to be caused by a difficulty to isolate an oily product, in which the mixture had to be cooled under $10^{\circ} \mathrm{C}$ to separate PBV well from methanol and to collect by decantation after washings with methanol. In fact, in the ${ }^{1} \mathrm{H}$ NMR spectra used for the calculation of the conversion, no obvious signal assigned to the side products was observed.

In the polymerizations of $\mathbf{E V}$ with the gels $\mathbf{1 a}-\mathbf{c}$, in which the content of $\mathrm{Y}$ was adjusted to be $1 \mathrm{~mol} \%$ to the monomer, the conversions of $\mathbf{E V}$ and the yields of PEV showed the high values over 95\% (Table II, Run 1-3). Even in the use of 1c showing the smallest element ratio of $\mathrm{Y}$ to $\mathrm{Si}$ such as $1 / 19$, the quantitative conversion and yield were recorded (Table II, Run 3). The increase of the molar ratios of Y to $\mathbf{E V}$ such as 5 and $10 \mathrm{~mol} \%$ in the use of $\mathbf{1 a}$ reasonably resulted in the quantitative formation of PEV (Table II, Run 6 and 7). The results demonstrated that the presence of only $1 \mathrm{~mol} \%$ of $\mathrm{Y}$ to $\mathbf{E V}$ was enough effective for the polymerization. It was one of the characteristic features in the use of the silicate gel that the concentration of the monomer $\mathbf{E V}$ in benzene rarely affected on the efficiency of the polymerization. When the polymerizations of $\mathbf{E V}$ were carried out in $3.4 \mathrm{M}$ benzene solution and without a solvent, the both yields of PEV were almost quantitative (Table II, Run 8 and 10). Even from the polymerization conducted in the diluted $0.9 \mathrm{M}$ benzene solution, PEV was obtained in $89 \%$ yield.

The $M_{\mathrm{n}} \mathrm{s}$ of PBV were estimated to be somewhat larger values over 7800 compared to those of PEVs. This seemed to be explained by the higher molecular weight of the monomer $\mathbf{B V}$. In the polymerizations of BV, the decrease of the conversion from $92 \%$ to $68 \%$ was observed, when the catalyst was changed from 1a to 1c (Table II, Run 4 and 5). In addition, in the use of BV, the yields of PBV decreased obviously with the increase of amount of the solvent (Table II, Run 1214). Such differences of the experimental facts between the polymerization of $\mathbf{E V}$ and $\mathbf{B V}$ were interpreted that the polymerization of $\mathbf{E V}$ primarily progressed on the surface of the silicate gel $\mathbf{1}$, but that of $\mathbf{B V}$ in a solution. This speculation was based on the steric effect of alkyl group involved in the monomer. The bulky butyl group should prevent the easy access of $\mathbf{B V}$ to the surface of the gel 1a. Whereas, EV can readily approach to the surface and, further, may be adsorbed on 1a. On the surface of the gel, the contact of the monomer with the active site neighboring yttrium should be favorable and the concentration of the substrates is possible. In the previous work, the possibility concerning such favorable effect of silica surface with the formation of ion pair intermediates was speculated. ${ }^{23}$ Namely, as mentioned on the results using the gel 1c, the silicate gel structure presented an appropriate reaction environment for $\mathbf{E V}$, but $\mathbf{B V}$ could not utilize it effectively due to the steric factor.

The results to examine the effects of solvent supported the above speculation. The polymerizations of $\mathbf{E V}$ conducted in dichloromethane, in which the concentrations of $\mathbf{E V}$ were adjusted to be $13.6 \mathrm{M}$ and $1.7 \mathrm{M}$, respectively, afforded PEVs quantitatively (Table III, Run 1 and 2). The results coincided with those observed in benzene solution. However, in the polymerizations using the polar solvents such as acetone and acetonitrile, the yields of PEV varied markedly. The yields of PEV decreased from 100\% to 62\% with the decreases of the concentration of the monomer from $13.6 \mathrm{M}$ to $1.7 \mathrm{M}$ in acetone (Table III, Run 3 and 4). In a similar manner, the successful for- 
mation of PEV was observed in $13.6 \mathrm{M}$ acetonitrile solution, but the polymerization of $\mathbf{E V}$ was failed in 1.7 M solution (Table III, Run 5 and 6). In the cases using BV, the use of polar solvents such as acetone and acetonitrile was obviously unfavorable. The polymerizations conducted in those polar solvents gave PBV in the lower yields such as $17 \%$ and $12 \%$ (Table III, Run 9 and 10). These results suggested that the polar solvents covered the active sites on 1a and/ or the cationic species generated from the monomer located around Y, and made the contact of the activated specie with other vinyl ether monomers difficult. Consequently, the unfavorable effects due to the polar solvents seemed to appear more clearly in the cases using $\mathbf{B V}$, which was difficult to stay on the surface of the gel by a steric hindrance of the bulky butyl group. The use of alcohols as the solvents gave unsuccessful results, in which no polymerization of $\mathbf{E V}$ progressed (Table III, Run 7 and 8). In these cases, the monomer was consumed completely, since no signal assigned to $\mathbf{E V}$ was detected in the ${ }^{1} \mathrm{H}$ NMR spectra after $8 \mathrm{~h}$ reaction. Although the detailed inspection on the spectra has not been done, the formation of acetal derivatives through the addition of the alcohol to EV was supposed. In addition, the catalyst was reusable. Even in the third use of 1a after calcinations at $700^{\circ} \mathrm{C}$ for $1 \mathrm{~h}$ before reusing, PEV was obtained almost quantitative yield (Table II, Run 15).

\section{CONCLUSION}

The gel obtained from $\mathrm{Na}_{2} \mathrm{SiO}_{3}$ and $\mathrm{YCl}_{3}$, which consisted of metal silicate structures, was shown to be a usable solid catalyst for the polymerization of the vinyl ethers. The use of the solid catalyst enabled the simple handling. In the case of $\mathbf{E V}$, after filtration of the silicate gel $\mathbf{1}$ and removal of voratile compounds by distillation under a reduced pressure, the pure PEV in the NMR spectral data was isolated. Furthermore, the catalyst $\mathbf{1}$ could be recycled at least third times without a loss of catalytic activity, although the calcination at $700^{\circ} \mathrm{C}$ was required before use.

The initiators for the polymerization were speculated to be silanol group and/or $\mathrm{H}_{2} \mathrm{O}$ contained as an impurity, which generate a cation specie. Although the following results have not been listed in this report, it may present the preliminary information on such mechanistic aspects of the polymerization. The additions of $1 \mathrm{~mol} \%$ of $n$-butylamine and 2, 6-dimethyl1-pyridine in the polymerization system using $\mathbf{E V}$ with 1a resulted in no formation of the polymeric product, but the conversions of $\mathbf{E V}$ were recorded to be $22 \%$ and $40 \%$, respectively. Thus, the basic reagent, which should neutralize the acid site, obviously inhibited the polymerization. In addition, the use of

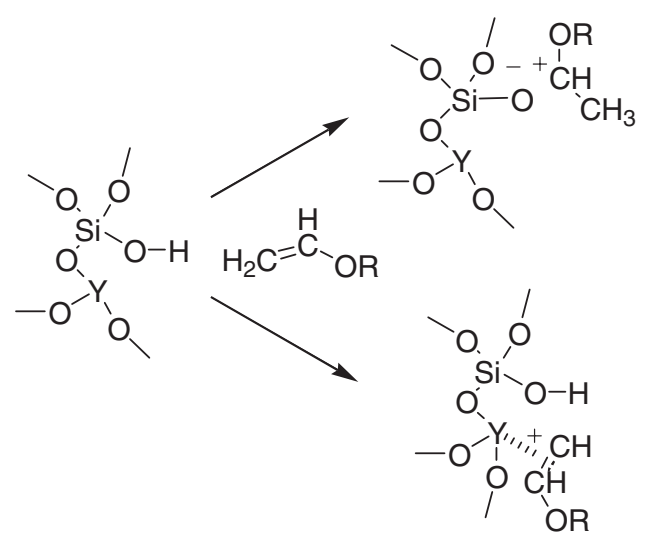

Scheme 2.

the later bulky base, which should show a difficulty to reach the active sites on the surface of 1a, led to the somewhat higher conversion of PEV compared to that observed in the use of less bulky $n$-butylamine. The results suggested that the initiating step proceeds on the surface of the silicate gel and the generated cation species stay around there, where the access of bulky substrate is unfavorable. Those speculated steps in the polymerization were shown in Scheme 2.

\section{REFERENCES}

1. M. Trost, I. Fleming, and S. L. Shreiber, "Comprehensive Organic Synthesis,” Pergamon Press, 1991, Vol. 1.

2. T. Imamoto, "Lanthanides in Organic Synthesis," Academic Press, 1991.

3. S. Agarwal, C. Mast, K. Dehnicke, and A. Greiner, Macromol. Rapid. Commun., 21, 195 (2000).

4. H. MA, T. Spaniol, and J. Okuda, Dalton Trans., 2003, 4770.

5. M. Kunioka, Y. Wang, and S. Onozawa, Polym. J., 35, 422 (2003).

6. E. Martin, Ph. Dubois, and R. Jerome, Macromolecules, 36, 5934 (2003).

7. L. Fan, L. Zhang, and Z. Shen, Polym. J., 36, 91 (2004).

8. S. Hayase, T. Ito, and M. Wada, J. Polym. Sci., Part A: Polym. Chem., 19, 2541 (1981).

9. K. Kageyama, S. Ogino, and T. Aida, Macromolecules, 31, 4069 (1998).

10. K. Kageyama, T. Tatsumi, and T. Aida, Polym. J., 31, 1005 (1999).

11. A. A. Vaidaya and V. G. Kumar, J. Appl. Polym. Sci., 70, 629 (1998).

12. D. C. Brown, "High-Peak-Powder Nd Glass Laser Systems," Springer-Verlag, Heiderberg, 1981.

13. H. Hasegawa and T. Higashumura, J. Polym. Sci., Polym. Chem. Ed., 18, 611 (1980).

14. T. Jin, S. Inoue, S. Tsutsumi, K. Machida, and G. Adachi, J. Non-Cryst. Solids, 223, 123 (1988).

15. T. Fujiyama, M. Hori, and M. Sasaki, J. Non-Cryst. Solids, 121, 273 (1990).

16. W. V. Moreshead, J.-L. R. Nogues, and H. Krabill, J. Non- 
Cryst. Solids, 121, 267 (1990).

17. A. N. Christensen, Z. Kristallogr., 209, 7 (1994).

18. O. Tzvetkov and N. Minkova, J. Mater. Sci., 35, 2435 (2000).

19. O. Moriya, S. Yamamoto, T. Sugizaki, J. Maeda, A. Kamejima, T. Kumon, and T. Kageyama, Polym. J., 37, 262 (2005).

20. R. Anwander, F. T. Edelmann, and W. A. Herrmann, "Orga- nolanthanoid Chemistry: Synthesis, Structure, Catalysis, Topics in Current Chemistry 179," Springer-Verlag, Berlin, 1996.

21. M. Biswas and N. G. Maity, J. Macromol.-Sci. Chem., A15, 1553 (1981).

22. G. B. Alexander, J. Am. Chem. Soc., 76, 2094 (1954).

23. S. Spange and H. Schültz, Makromol. Chem., 194, 1537 (1993). 